\title{
Effect of aerobic exercise on blood hemoglobin level and quality of life in postmenopausal anemic women: randomized controlled clinical trial
}

\author{
Ahmed M. ELSHERIF ${ }^{\star 凶 1}$, Atef A. ALY ${ }^{2}$, and Amel M. YOUSEF ${ }^{3}$ \\ ${ }^{1}$ MSc Student at Women's Health Department, Faculty of Physical Therapy, Cairo University, Egypt \\ ${ }^{2}$ Professor and Head of Tropical Medicine Department, Faculty of Medicine, Menoufia University, Egypt \\ ${ }^{3}$ Professor of PT for Women's Health, Faculty of Physical Therapy, Cairo University, Egypt \\ Corresponding author's Email: rachago24@gmail.com; (D) ORCID: 0000-0002-5731-3046
}

\section{ABSTRACT}

Introduction. Postmenopausal elderly women have an increased risk for nutritional anemia. Exercise training has a positive effect on hemoglobin mass by increasing stimulation of erythropoiesis, which assists the blood to carry bigger amount of oxygen. Aim. This study has been conducted to investigate the effect of moderate intensity aerobic exercises on hematological value and quality of life in postmenopausal anemic women. Methods. Thirty anemic postmenopausal women were assigned randomly into two equal groups; A) performed moderate intensity aerobic exercise in the form of walking on treadmill for 30 minutes, 3 sessions per week and B) without aerobic exercise. Both groups received the same supplement including one capsule that contain Iron supplement $(10 \mathrm{mg})$ and multi vitamins as well as essential trace elements, daily. The hematological values [hemoglobin $(\mathrm{Hb})$ and red blood corpuscles (RBCs) count] and assessment of the quality of life [Six-Minute Walk Test (SMWT) and Flow State Scale (FSS)] at pre and post 3 months as well as 6 months of treatment were measured and evaluated. Results. There was statistically significant improvement $(\mathrm{p}<0.001)$ in the $\mathrm{Hb}$ and RBCs values and SMWT and FSS between before and after 3 as well as 6 months of treatment in both groups. Also, comparison between both groups at 3 and 6 months showed significant differences in favors of group A. Conclusion. Aerobic exercise can increase hematological values and has a positive improvement for the quality of life in anemic post-menopausal women.

\author{
Original Article \\ PII: S225199392100007-11 \\ Rec. 24 March 2021 \\ Rev. 30 April 2021 \\ Acc. 25 May 2021
}

\section{Keywords}

Anemia,

Menopause,

Exercise,

Flow State Scale,

Six Minute Walk Test

\section{INTRODUCTION}

Anemia is commonly found in the elderly. Undiagnosed and untreated anemia can have severe consequences and is associated with an increased risk of mortality, poor health, and decreased physical function [ 1 , 2]. According to cause, anemia subdivided into 4 types: unexplained anemia, nutrient deficiencies anemia, chronic disease or inflammation and chronic kidney disease [3, 4]. Anemia may lead to serious diseases, such as gastrointestinal cancer or vitamin B 12 deficiency, which may have severe implications if not managed appropriately $[1,5]$.

In addition to age, sex is a factor that has been shown to influence the prevalence of anemia in the elderly. Findings have shown that before age 55, the prevalence of anemia was lower in men than in women (approximately 3\% in men compared with 6\% in women aged 50-54) [1]. Anemia can be diagnosed at laboratory, as evidence of low iron stores. As, it is two standard deviations below normal of Hb level for age and sex [6-9]. Aerobic exercise training can be used effectively for improving symptoms of fatigue and quality of life for cancer patients treated with hematopoietic stem cell therapy [10].

Erythrocyte levels in females treated for breast cancer can be preserved during radiation using moderate intensity aerobic exercise compared with declines observed in untrained. So, during radiation treatment of breast cancer there is an association between erythrocyte values and fitness. So, for improving physical fitness and maintaining erythrocyte levels in females receiving radiation treatment of breast cancer, it is safe, effective, and economical to use moderate aerobic exercise [11]. So, the purpose of this study was to determine the effect of aerobic exercise on hemoglobin ( $\mathrm{Hb}$ ) level, red blood corpuscles (RBCs) count, and quality of life in postmenopausal anemic women as, there is no published study until now. 


\section{Subjects}

Thirty postmenopausal anemic women enrolled in this study from Outpatient Clinic of Gynecology, Sadat City Central Hospital. Their ages ranged between 50-60 years and body mass index $<30 \mathrm{~kg} / \mathrm{m}^{2}$. For participation in this study patients were suffered from moderate anemia as their $\mathrm{Hb}$ was $<10 \mathrm{~g} / \mathrm{dl}$ without explained cause and they were medically stable. Patients having acute gastrointestinal diseases, bleeding of unknown cause, cancer, chronic kidney problems, chronic inflammation, bone marrow or stem cells problems, cardiovascular or pulmonary diseases and any musculoskeletal dysfunction that can limit their mobility were excluded from participation in this study.

All participants were completely understood the study protocol and the objectives of the study and signed consent form before participation and were asked not to make any change of their pharmacologic treatment, general eating routine, and continue their daily activities as well as lifestyle all through the study period.

\section{Design of the study}

After patients fulfilled the inclusion criteria of the study, they were assigned randomly into two equal matched groups A and B using an envelope prepared by an independent individual using random number generation to make randomization. Group A performed moderate intensity aerobic exercise in the form of walking on treadmill for 30 minutes, 3 sessions per week and received iron supplement and group B followed the same iron supplement like group A.

Both groups were evaluated at pre and post 3 as well as 6 months of treatment via measuring hemoglobin $(\mathrm{Hb})$ and red blood corpuscles (RBCs) count [12]. And the quality of life using Six-Minute Walk Test (SMWT) which has a valuable and important role to assess the functional exercise capacity if progressed or regressed [13-15] was assessed. Flow State Scale (FSS) was also assessed to measure the flow in physical activity which consists of 36 items that represent the dimension of flow in physical activity. There were five choices for each item that the patient chooses the most suitable to her current state [16].

\section{Treatment procedures}

Each woman in both groups received the same medical treatment in the form of one capsule daily, that contain iron supplement ( $10 \mathrm{mg})$ and multi vitamins $(\mathrm{B} 1=0.6 \mathrm{mg} ; \mathrm{B} 2=0.6 \mathrm{mg} ; \mathrm{B} 6=0.6 \mathrm{mg} ; \mathrm{B} 12=1.2 \mathrm{mc}$ and $\mathrm{C}=30$ $\mathrm{mg}$ ) as well as essential trace elements (Zinc $=5 \mathrm{mg}$; Copper=0.44 mg; Folic acid=200 mc and Biotin=12 mc for 6 months [7]. In addition, group A participated in moderate intensity walking on electric treadmill model LEOPARD 3030 with AC motor and its speed of $1-12 \mathrm{~km}$ and dimensions is $165 \times 69 \times 130 \mathrm{~cm}$, also it has shock absorber for absorbent of high impact shocks and safety, with display screen for showing time in minutes and speed in kilometers per hour and hand-held pulse measurement by hand attached to it for easily monitoring of heart rate). The training was adjusted at 50\% of target heart rate in the $1^{\text {st }}$ two months which increased to $60 \%$ in next 2 months and $70 \%$ in the last two months of training. Target heart rate was calculated for each woman in group A using the following equation:

Target Heart Rate $=[($ maximum heart rate - resting heart rate $) \times \%$ Intensity $)+$ resting heart rate Maximum heart rate $=220$ - age (years) [17].

Aerobic exercise training was done for 30 minutes, day after day (3 sessions weekly) for 6 months. Each session started by warming up phase that was walking on treadmill for 5 minutes at $20 \%$ of target heart rate. Active phase after warming up was walking on treadmill for 20 min at 50-70\% of target heart rate. And cooling down phase after the active phase of exercise was walking on treadmill for 5 minutes at $20 \%$ of the target heart rate $[17,18]$.

\section{Statistical analysis}

For making comparison of the subject characteristics between groups, Descriptive statistics and unpaired t-test were conducted. ANOVA with repeated measures was conducted for comparison Hb, RBCs count, SMWT and FSS between pre-treatment, 3 months and 6 months in each group and unpaired test was carried out for comparison between groups. $\mathrm{P}$ value < 0.05 was the level of significance for all statistical tests done. All statistical analysis was conducted through the statistical package for social studies (SPSS) version 25 for windows (IBM SPSS, Chicago, IL, USA). 


\section{Ethical approval}

The review board and ethics committee of faculty of physical therapy, Cairo University approved the study protocol (encoded: P.T.REC/012/002318 at 31-03-2019 to Ahmed Moustafa Mahmoud Elsherif) and informed consents were taken from all the participants. Ethical approval

\section{RESULTS}

Table 1 showed the subject characteristics of both groups (A and B). According to age, weight, height and BMI, there was no significant difference between groups $(\mathrm{P}>0.05)$.

Within group comparison there was a significant increase in Hb and RBCs counts, SMWT and FSS values in both groups between 3 months post treatment with pre-treatment $(\mathrm{P}<0.001)$ and also 6 months post treatment when compared with pre-treatment $(\mathrm{P}<0.001)$ and 3 months post treatment $(\mathrm{P}<0.001)$ (Table 4$)$.

Between groups comparison there was no significant difference between groups in pre-treatment or control ( $p>0.05$ ). While, there was a significant increase in Hb and RBCs counts, as well as SMWT and FSS values of the group $A$ at 3 months $(P<0.001)$ and 6 months post-treatment $(P<0.001)$ when compared to group B (Table 2).

Table 1. Basic characteristics of participants.

\begin{tabular}{|c|c|c|c|}
\hline \multirow{2}{*}{ Variables } & Group A) & Group B & \multirow{2}{*}{ P-value } \\
\hline & Mean \pm SD & Mean \pm SD & \\
\hline Age (years) & $54.8 \pm 2.45$ & $53.93 \pm 2.81$ & 0.37 \\
\hline Weight (kg) & $76.78 \pm 4.72$ & $75.95 \pm 4.1$ & 0.61 \\
\hline Height (cm) & $164 \pm 3.79$ & $163.4 \pm 3.64$ & 0.66 \\
\hline $\mathrm{BMI}\left(\mathrm{kg} / \mathrm{m}^{2}\right)$ & $28.53 \pm 1.28$ & $28.44 \pm 1.26$ & 0.84 \\
\hline
\end{tabular}

$\mathrm{SD}=$ standard deviation; $\mathrm{p}$-value= level of significance

Table 2. Mean $\mathrm{Hb}, \mathrm{RBC}$ count, SMWT and FSS at pre-treatment, 3 months and 6 months post treatment of group (A \& B).

\begin{tabular}{|c|c|c|c|c|c|c|c|}
\hline \multirow{2}{*}{ Variables } & & \multirow{2}{*}{$\begin{array}{c}\text { Pre treatment } \\
\text { mean } \pm \text { SD }\end{array}$} & \multirow{2}{*}{$\begin{array}{c}3 \text { months } \\
\text { post treatment } \\
\text { mean } \pm S D\end{array}$} & \multirow{2}{*}{$\begin{array}{c}6 \text { months } \\
\text { post treatment } \\
\text { mean } \pm \mathrm{SD}\end{array}$} & \multicolumn{3}{|c|}{ P-value } \\
\hline & & & & & $\begin{array}{l}\text { Pre vs } 3 \\
\text { months }\end{array}$ & $\begin{array}{l}\text { Pre vs } 6 \\
\text { months }\end{array}$ & $\begin{array}{l}3 \text { months vs } \\
6 \text { months }\end{array}$ \\
\hline \multirow{3}{*}{$\mathrm{Hb}(\mathrm{gm} / \mathrm{dl})$} & Group A & $9.21 \pm 0.43$ & $12.51 \pm 0.57$ & $14.1 \pm 0.44$ & 0.001 & 0.001 & 0.001 \\
\hline & Group B & $9.4 \pm 0.36$ & $11.61 \pm 0.55$ & $12.6 \pm 0.49$ & 0.001 & 0.001 & 0.001 \\
\hline & & $P=0.19$ & $P=0.001$ & $P=0.001$ & & & \\
\hline \multirow{3}{*}{$\begin{array}{l}\text { RBCs count } \\
(106 / \mu l)\end{array}$} & Group A & $3.7 \pm 0.21$ & $4.4 \pm 0.17$ & $4.7 \pm 0.19$ & 0.001 & 0.001 & 0.001 \\
\hline & Group B & $3.78 \pm 0.24$ & $4.15 \pm 0.26$ & $4.34 \pm 0.2$ & 0.001 & 0.001 & 0.005 \\
\hline & & $\mathrm{P}$-value $=0.33$ & $\mathrm{P}$-value $<0.005$ & P-value < 0.001 & & & \\
\hline \multirow{3}{*}{ SMWT (m) } & Group A & $450.06 \pm 7.11$ & $581.4 \pm 6.8$ & $635 \pm 6.22$ & 0.001 & 0.001 & 0.001 \\
\hline & Group B & $452 \pm 7.34$ & $540.53 \pm 5.51$ & $574.6 \pm 6.82$ & 0.001 & 0.001 & 0.001 \\
\hline & & $\mathrm{P}$-value $=0.47$ & P-value $<0.001$ & P-value < 0.001 & & & \\
\hline \multirow{3}{*}{ FSS } & Group A & $101.4 \pm 7.21$ & $139.86 \pm 3.44$ & $162 \pm 3.87$ & 0.001 & 0.001 & 0.001 \\
\hline & Group B & $101.66 \pm 5.88$ & $124.6 \pm 4.03$ & $136.86 \pm 4.43$ & 0.001 & 0.001 & 0.001 \\
\hline & & $P$-value $=0.91$ & $\mathrm{P}$-value $<0.001$ & $P$-value $<0.001$ & & & \\
\hline
\end{tabular}

$\mathrm{SD}=$ Standard deviation; $\mathrm{P}$-value $=$ level of significance

\section{DISCUSSION}

This study aimed to investigate the effect of moderate intensity aerobic exercises on hematological value (RBCs and $\mathrm{HB}$ ) and quality of life in postmenopausal anemic women. According to the findings, there was a significant increase in $\mathrm{Hb}, \mathrm{RBC}$ s count, SMWT and FSS in both groups ( $\mathrm{A}$ and $\mathrm{B}$ who received the same medical treatment) at 3 months post treatment compared with pre-treatment or control $(\mathrm{P}<0.001)$ and at 6 months post treatment compared with both control $(\mathrm{P}<0.001)$ and 3 months post treatment $(\mathrm{P}<0.001)$. In addition, a significant increase in $\mathrm{Hb}$ and RBCs counts, as well as SMWT and FSS of the group A patients who performed moderate 
intensity aerobic exercise in the form of walking on treadmill for 30 minutes, 3 sessions per week after 3 months $(\mathrm{P}<0.001)$ and 6 months $(\mathrm{P}<0.001)$ in compared with the group $\mathrm{B}$ patients who didn't perform any aerobic exercise.

Based on the positive effect of exercise on the $\mathrm{Hb}$, many studies could be correlated with the results of the present study, but they have different causes for anemia and age as mentioned by Drouin et al. [11], who investigated the effect of aerobic exercise on erythrocyte levels in cases of breast cancer who receive radiation treatment. They found that moderate intensity aerobic exercise had positive effect on patients compared with patients who did not perform, as it assist to maintain erythrocyte levels during radiation treatment of breast cancer compared with the declines in erythrocyte levels showed in patients who didn't perform.

Also, Mohamady et al. [19] investigated the effect of aerobic exercise on elderly women suffered from anemia related to breast cancer and underwent chemotherapy. After receiving aerobic program for 25-40 min at 50-70\% of the maximum heart rate, 3 times/week for 12 weeks in addition to medication, nutritional support and usual activities of daily living for intervention group compared with control group which received medication, nutritional support in addition to usual activities of daily living only. There was significant improvement in mean values of $\mathrm{Hb}$ and $\mathrm{RBCs}$ in the intervention group compared with the control group. Hu and Lin [20] and Mairbäurl [21] stated that exercise training stimulates and improves erythropoiesis which raises total $\mathrm{Hb}$ and $\mathrm{RBCs}$ mass, which improves oxygen carrying capacity. Also, Wilson et al. [10] reported that the aerobic exercise performed at home for 20-40 min at target heart rate (40-60\% predicted heart rate reserve) for 3-5 sessions per week for a period of 12 weeks is effective and safe to improve physical functioning and fatigue in sedentary hematopoietic stem cell transplant recipients. In addition, Penninx et al. [22] revealed a relation between anemia and disability, physical capacity, and muscle power in older population in the Chianti area in Italy. they performed the study was 1,156 participants with 65 and older ages and found an increase in the $\mathrm{Hb}$ and energy value which indicates that exercise enhances erythropoiesis as well as elevation of reticulocytes counts which can be observed within 1-2 days after endurance and strength training.

On the other hand, few studies did not find any effect of exercise on anemia but also the participant cases were not the same inclusion criteria in the present study. Cicek [23] compared the effect of aerobic exercises and strength exercises on hematological parameters in sedentary women and found that Hb and hematocrit values decreased and the platelet count and mean corpuscular volume (MCV) values increased in the strength exercise group compared to aerobic exercise group. Also, Fujitsuka et al. [24] examined hematological and biochemical parameters of soldiers who participated in training program for a period of 12 weeks. They observed that there is anemia or decrease in the $\mathrm{Hb}$ concentrations in healthy individuals after various intensities of sports and physical exercise.

\section{CONCLUSION}

Moderate intensity aerobic exercise has valuable effects on post-menopausal anemic women and their quality of life as evidenced by the significant increase in mean values of $\mathrm{Hb}$, RBCs, FSS and SMWT. In turn, these results could provide healthcare professionals with an appropriate non-pharmacologic intervention to counteract the decline in erythrocyte observed in many post-menopausal anemic patients.

\section{DECLARATIONS}

\section{Acknowledgements}

This work was supported by Outpatient Clinic of Faculty of Physical Therapy, Cairo, Egypt and Outpatient Clinic of Gynecology, Sadat City Central Hospital, Sadat city, Egypt. No words could ever express my sincere gratitude and deep appreciation to Prof. Dr. Amel Mohammed Yousef, professor of physical therapy for women's health, Faculty of Physical Therapy Cairo University. She gave me a great deal of her valuable time and effort to accomplish this work. Her comments and guidance were very helpful and beneficial for me. Special and deepest thanks to Prof. Dr. Atef Abo Alsoud Aly, Professor and Head of Tropical Medicine Department, Faculty of Medicine, Menoufia University.

\section{Authors' contributions}

All authors contributed equally to this work.

\section{Competing interests}

The authors declare that they have no competing interests. 


\section{REFERENCES}

1. Balducci L. Epidemiology of anemia in the elderly: information on diagnostic evaluation. Journal of the American Geriatrics Society. 2003; 51(3s): 2-9. DOI: https://doi.org/10.1046/j.1532-5415.51.35.4.x

2. Gaskell H, Derry S, Moore R, and Mcquay H. Prevalence of anaemia in older persons: systematic review. Biomed Central Geriatrics. 2008; 8 (1):1. DOI: https://doi.org/10.1186/1471-2318-8-1

3. Patel K. Epidemiology of Anemia in Older Adults. Semin Hematol. 2008; 45(4): $210-217$. DOI: https://doi.org/10.1053/j.seminhematol.2008.06.006

4. Tettamanti M, Lucca U, Gandini F, Recchia A and Mosconi P. Prevalence, incidence and types of mild anemia in the elderly: the "Health and Anemia" population-based study. Haematologica, 2010; 95(11): $1849-1856$. DOI: https://doi.org/10.3324/haematol.2010.023101

5. Vanasse G and Berliner N. Anemia in Elderly Patients: An Emerging Problem for the 21st Century. Hematology Am Soc Hematol Educ Program. 2010; 1: 271-275. DOI: https://doi.org/10.1182/asheducation-2010.1.271

6. Beutler $\mathrm{E}$ and Waalen J. The definition of anemia: what is the lower limit of normal of the blood hemoglobin concentration? Blood journal. 2006; 107(5): 1747-1750. DOI: https://doi.org/10.1182/blood-2005-07-3046

7. Short, M. and Domagalski, J. (2013), "Iron Deficiency Anemia: Evaluation and Management", American Family Physician, 87(2): 98-104. https://www.aafp.org/afp/2013/0115/pg8.html

8. Khansa Q, Muhammad S, Fatima Q, Shafi M. et al, Malabsorption of iron as a cause of iron deficiency anemia in postmenopausal women. Pakistan Journal of Medical Sciences. 2015; 31(2):304-308. DOI: https://doi.org/10.12669/pjms.312.6462

9. Tefferi A. Anemia in Adults: A Contemporary Approach to Diagnosis. Mayo Foundation for Medical Education and Research. 2003; 78: 1274-1280. DOI: https://doi.org/10.4065/78.10.1274

10. Wilson R, Jacobsen $\mathrm{P}$, and Fields $\mathrm{K}$. Pilot study of a home-based aerobic exercise program for sedentary cancer survivors treated with hematopoietic stem cell transplantation Bone Marrow Transplantation. 2005; 35: $721-727$. DOI: https://doi.org/10.1038/sj.bmt.1704815

11. Drouin J, Young T, Beeler J, Byrne K, Birk T., et al. Random control clinical trial on the effects of aerobic exercise training on erythrocyte levels during radiation treatment for breast cancer. Cancer. American cancer society. 2006; 107(10): 2490-2495. http://dx.doi.org/10.1002/cncr.22267.

12. Harris R, Barton G, Caswell M, Ellison P, Lloyd H, et al. Anaemia on full blood count: investigating beyond the pale. Best tests. 2013; 9: 3-17. https://bpac.org.nz/BT/2013/September/docs/BestTests20.pdf

13. Bautmans I, Lambert $M$ and Mets T. The six-minute walk test in community dwelling elderly: influence of health status. Biomedical Central Geriatrics. 2004; 4:6. DOI: https://doi.org/10.1186/1471-2318-4-6

14. Peel C and Ballard D. Reproducibility of the 6-Minute-Walk Test in older Women. Journal of Aging and Physical Activity. 2001; 9(2): 184-193. DOI: https://doi.org/10.1123/japa.9.2.184

15. Rikli R. and Jones J.C. The reliability and validity of a 6 -minute walk test as a measure of physical endurance in older adults. Journal of Aging and Physical Activity. 1998; 6: 363-375. DOI: https://doi.org/10.1123/japa.6.4.363

16. Jackson S. and March H. Development and validation of a scale to measure optimal experience: The Flow StateScale. Journal of Sport and Exercise Psychology. 1996; 18: 17-19. DOI: https://doi.org/10.1123/jsep.18.1.17

17. Kisner C, Colby L. and Borstad J. Principles of Aerobic Exercise. Therapeutic exercise: foundations and techniques. ISBN 9780803658509. 2018. Google Scholar

18. Clayton N, Drake J, Larkin S, Linkul R, Martino M, Nutting M and Tumminello N. (2015;), "Foundations of fitness programming. National Strength and Conditioning Association, PP. 9-23. Available at Link

19. Mohamady $\mathrm{H}$, Elsisi $\mathrm{H}$ and Aneis $\mathrm{Y}$. Impact of moderate intensity aerobic exercise on chemotherapy-induced anemia in elderly women with breast cancer: A randomized controlled clinical trial. Journal of Advanced Research 2017; 8: 7-12. DOI: https://doi.org/10.1016/j.jare.2016.10.005

20. Hu M and Lin W. Effects of Exercise Training on Red Blood Cell Production: Implications for Anemia. Acta Haematol, 2012; 127: 156-164. DOI: https://doi.org/10.1159/000335620

21. Mairbäurl H. Red blood cells in sports: effects of exercise and training on oxygen supply by red blood cells. Frontiers in Physiology. 2013; 4(332): 1-13. https://doi.org/10.3389/fphys.2013.00332

22. Penninx B, Pahor M, Cesari M, Corsi A, Woodman R, et al. Anemia is associated with disability and decreased physical performance and muscle strength in the elderly. Journal of American Geriatrics Society. 2004; 52(5): 719-724. DOI: https://doi.org/10.1111/j.1532-5415.2004.52208.x

23. Cicek $G$. The effects of different exercise types on hematological parameters in sedentary women. Journal of Education and Training Studies. 2018; 6(8):96. DOI: https://doi.org/10.11114/jets.v6i8.3374

24. Fujitsuka S, Koike $Y$, Isozaki A and Nomura Y. Effect of 12 weeks of strenuous physical training on hematological changes. Military Medicine. 2005; 170(7): 590-594. DOI: https://doi.org/10.7205/milmed.170.7.590 